\title{
Adverse Effects of Morphine and Fentanyl for Stomatitis in Patients Receiving Allogeneic Hematopoietic Cell Transplantation-A Single Center Retrospective Analysis
}

\author{
Mayuko Koshino, Yasushi Okoshi, Naoki Kurita, Naoshi Obara, Kazumi Suzukawa, \\ Yuichi Hasegawa, Shigeru Chiba \\ Department of Hematology, University of Tsukuba, Tsukuba, Japan. \\ Email: yokoshi@md.tsukuba.ac.jp,schiba-tky@umin.net
}

Received September $9^{\text {th }}, 2012$; revised October $29^{\text {th }}, 2012$; accepted November $8^{\text {th }}, 2012$

\begin{abstract}
Opioids are widely used as analgesics for oral mucositis in allogeneic hematopoietic cell transplantation (allo-HCT). Their main adverse events are nausea, vomiting, constipation, psychological symptoms, and respiratory depression. In our institute, continuous intravenous morphine was generally used until 2007, followed by intravenous fentanyl as the first-line agent because of its potential fewer adverse events. We retrospectively analyzed 99 patients who underwent allo-HCT in the University of Tsukuba Hospital from 2004 to 2009. Out of 99 patients, 64 were treated with opioids (morphine, 32 and fentanyl, 32). The attending physicians were in charge of providing stable pain control. Median age, sex, stem cell source, preparative regimen, and GVHD prophylaxis were similar in the two groups. There were no significant differences in psychological symptoms, drowsiness, nausea, and vomiting in both groups. Defecation ratio (the days having a bowel movement/the days taking opioids) was $63 \%$ and $94 \%$ in the morphine and fentanyl group, respectively $(\mathrm{P}<0.0001)$. The percentage of patients who needed to use purgative drugs was $25 \%$ and $6 \%$ in the morphine and fentanyl group, respectively $(\mathrm{P}=0.04)$. It is suggested that fentanyl has less adverse effects on gastrointestinal movement and is safer than morphine when used for oral mucositis in allo-HCT.
\end{abstract}

Keywords: Stomatitis; Morphine; Fentanyl; Allo-HCT; Constipation

\section{Introduction}

Pain management for oral mucositis is important in hematopoietic cell transplantation (HCT) to maintain patient's condition and quality of life. Insufficient pain management leads to inadequate oral care and difficulty with food intake. Moreover, it can cause dehydration, malnutrition, and serious infections [1], and has been linked to inferior overall survival after HCT [2]. With conventional conditioning regimens, and in particular by the use of methotrexate for graft-versus-host disease prophylaxis, most of the patients experience oral mucositis at some degree within 3 - 5 days after HCT [3]. Oral mucositis is usually resolved after engraftment. For around twenty days before engraftment, continuous intravenous infusion of opioid is a choice of treatment. Currently, morphine and fentanyl are widely used for pain control in HCT. In this institute, intravenous morphine was used until 2007 in most cases as the first line opioid, which was then gradually substituted by intravenous fentanyl because constipation caused by morphine was thought to be problematic.
We now retrospectively compared the adverse effects and effectiveness against oral mucositis of morphine and fentanyl in patients who received allogeneic HCT.

\section{Patients and Methods}

\subsection{Patients}

We reviewed 64 cases that were treated with intravenous opioids for oral mucositis out of 99 HCT cases in Hematology Division of University of Tsukuba Hospital from 2004 to 2009 . Each attending physician decided to start opioids based on the severity of mucositis and patients' needs for pain management. The dose of opioid was adjusted to the minimum dose to obtain sufficient effect. Based on CTCAE version 4.0, adverse events such as nausea, vomiting, psychological symptoms, and drowsiness were evaluated and considered significant if grade 2 or more. Defecation ratio was defined as "the days having a bowel movement/the days taking opioids". As another surrogate marker of constipation, proportion of patients who took purgative drugs in each group was also evaluated. 


\subsection{Statistical Analysis}

Differences between variables were evaluated using the Student $t$-test using the Statcel software (OMS, Saitama, Japan). P value $<0.05$ was considered statistically significant.

\section{Results}

\subsection{Patients' Characteristics (Table 1)}

There were no statistical differences in median age, sex, graft source, preparative regimen, and GVHD prophylaxis between the two groups, while a larger number of acute lymphoblastic leukemia (ALL) patients were inclu- ded in the morphine group $(\mathrm{P}<0.01)$. The median duration using opioids was 15.0 (2 - 38) and 15.5 days (4 - 32 days) in the morphine and fentanyl group, respectively.

\subsection{Adverse Events of Morphine and Fentanyl}

There were no significant differences in nausea, vomiting, psychological symptoms, and drowsiness between the two groups (Table 2). Psychological symptoms and drowsiness tended to be seen more in the morphine group, particularly at higher doses, but the number of the patients was too small for the statistical comparison (Tables 2 and 3).

The median defecation ratio was $63 \%$ (range, $5 \%$ -

Table 1. Patient characteristics.

\begin{tabular}{|c|c|c|}
\hline & Morphine & Fentanyl \\
\hline Dosage, median (range) & $30 \mathrm{mg} /$ day $(10-100)$ & $0.75 \mathrm{mg} /$ day $(0.2-1.5)$ \\
\hline Duration of use, median (range) & 15.0 days $(2-38)$ & 15.5 days $(4-32)$ \\
\hline Number of patients & 32 & 32 \\
\hline Median age & $40(17-54)$ & $39.5(18-60)$ \\
\hline \multicolumn{3}{|l|}{ Sex } \\
\hline Male & 15 & 17 \\
\hline Female & 17 & 15 \\
\hline \multicolumn{3}{|l|}{ Disease type } \\
\hline AML & 8 & 9 \\
\hline ALL & 10 & 5 \\
\hline MDS & 4 & 11 \\
\hline CML & 3 & 2 \\
\hline Others & 3 & 4 \\
\hline \multicolumn{3}{|l|}{ Stem cell source } \\
\hline rBMT & 4 & 7 \\
\hline urBMT & 21 & 19 \\
\hline rPBSCT & 5 & 4 \\
\hline $\mathrm{CBT}$ & 2 & 2 \\
\hline \multicolumn{3}{|l|}{ Conditioning regimen } \\
\hline $\mathrm{CY}+\mathrm{TBI}$ & 22 & 19 \\
\hline $\mathrm{BU}+\mathrm{CY}$ & 2 & 2 \\
\hline Flu + L-PAM & 3 & 5 \\
\hline Others & 5 & 6 \\
\hline \multicolumn{3}{|l|}{ GVHD prophylaxis } \\
\hline FK506 + MTX & 23 & 22 \\
\hline CyA + MTX & 7 & 8 \\
\hline Others & 2 & 2 \\
\hline
\end{tabular}

Abbreviations: AML, acute myeloid leukemia; ALL, acute lymphoblastic leukemia; MDS, myelodysplastic syndrome; CML, chronic myelogenous leukemia; r, related; ur, unrelated; CBT, cord blood transplantation; CY, cyclophosphamide; TBI, total body irradiation; BU, busulfan; Flu, fludarabine; MTX, methotrexate; CyA, cyclosporine A. 
Hematopoietic Cell Transplantation-A Single Center Retrospective Analysis

Table 2. Adverse events of morphine and fentanyl.

\begin{tabular}{cccc}
\hline & Morphine $(\mathrm{n}=32)$ & Fentanyl $(\mathrm{n}=32)$ & $\mathrm{P}$ \\
\hline Psychological symptoms & 2 & 2 & 0.69 \\
Drowsiness & 2 & 2 & 0.15 \\
Nausea & 1 & 1 & 0.15 \\
Vomiting & 1 & & 0.31 \\
Constipation $\rightarrow$ Table 4 & & & \\
\hline
\end{tabular}

CTCAE Grade 2 or more adverse events were summarized.

Table 3. Dose comparison of morphine or fentanyl with or without psychological symptoms or drowsiness.

\begin{tabular}{|c|c|c|c|}
\hline & \multicolumn{2}{|c|}{ Psychological symptoms } & \multirow{2}{*}{$\mathrm{P}$} \\
\hline & $(+)$ & $(-)$ & \\
\hline Morphine, average dose, $\mathrm{mg} / \mathrm{day}$ & $65(\mathrm{n}=2)$ & $37(\mathrm{n}=30)$ & 0.46 \\
\hline \multirow[t]{3}{*}{ Fentanyl, average dose, mg/day } & $0.74(\mathrm{n}=2)$ & $0.65(\mathrm{n}=30)$ & 0.79 \\
\hline & \multicolumn{2}{|c|}{ Drowsiness } & \multirow{2}{*}{$\mathrm{P}$} \\
\hline & $(+)$ & $(-)$ & \\
\hline Morphine, average dose, $\mathrm{mg} / \mathrm{day}$ & $60(\mathrm{n}=2)$ & $30(\mathrm{n}=30)$ & 0.45 \\
\hline Fentanyl, average dose, $\mathrm{mg} /$ day & $-(\mathrm{n}=0)$ & $0.66(\mathrm{n}=32)$ & - \\
\hline
\end{tabular}

$100 \%)$ and $94 \%(36 \%-100 \%)$ in the morphine and fentanyl group, respectively $(\mathrm{P}<0.0001)$ (Table 4). The proportion of patients using purgative drugs was $25 \%$ and $6 \%$ in the morphine and fentanyl group, respectively $(\mathrm{P}=0.04)$ (Table 4). A case in the morphine group developed paralytic ileus. Briefly, a 17-year-old female suffering from ALL was administered with morphine for oral mucositis on post-transplant day 5 . The patient shortly developed constipation and was refractory to laxative therapies. From day 15, she complained of nausea and abdominal distension, and developed severe vomiting, which needed frequent antiemetic agents. Abdominal X-ray revealed paralytic ileus. The symptoms were improved rapidly after reduction of morphine.

\subsection{Reasons for Discontinuation of Opioids}

Three patients in the morphine group and 4 in the fentanyl group needed to reduce or discontinue the opioids (Table 5). In the morphine group, the reasons were nausea, headache, and delirium; in contrast, ineffectiveness, hallucination, and "expectation for relieving dyspnea by morphine" in the fentanyl group. In the two cases in which fentanyl were ineffective, the pain could not be controlled sufficiently even after replacement with morphine.
Table 4. Evaluation of constipation.

\begin{tabular}{|c|c|c|c|}
\hline & $\begin{array}{l}\text { Morphine } \\
(\mathrm{n}=32)^{*}\end{array}$ & $\begin{array}{l}\text { Fentanyl } \\
(\mathrm{n}=32)\end{array}$ & $\mathrm{P}$ \\
\hline Defecation ratio & $\begin{array}{c}63 \% \\
(5 \%-100 \%)\end{array}$ & $\begin{array}{c}94 \% \\
(36 \%-100 \%)\end{array}$ & $<0.0001$ \\
\hline $\begin{array}{l}\text { Patients taking } \\
\text { purgative drugs }\end{array}$ & $25 \%(\mathrm{n}=8)$ & $6 \%(\mathrm{n}=2)$ & 0.04 \\
\hline
\end{tabular}

*One case developed paralytic ileus.

Table 5. Reasons for discontinuation.

\begin{tabular}{cccc}
\hline & Morphine & Fentanyl & $\mathrm{P}$ \\
\hline Ineffectiveness & 0 & 2 & 0.15 \\
Nausea & 1 & 0 & 0.31 \\
Headache & 1 & 0 & 0.31 \\
Hallucination & 0 & 1 & 0.31 \\
Delirium & 1 & 0 & 0.31 \\
Others & 0 & 1 & 0.31 \\
Total & 3 & 4 & 0.45 \\
\hline
\end{tabular}

\section{Discussion}

The influence of oral morphine and transdermal fentanyl on constipation has been compared in some clinical trials. 
In these studies, morphine was reported to develop constipation more frequently or require more laxatives than fentanyl [4-6]. The cause of these results was attributed to differences in the distribution of the opioids in blood and brain, depending on the lipid solubility [7]. To the best of our knowledge, there has been no previous report on the comparison of continuous intravenous morphine and fentanyl for stomatitis after HCT. Morphine has been preferentially used in the post-HCT stomatitis probably because anti-diarrheic effect, in addition to analgesic effect, is expected, given that the period of oral mucositis overlaps that of intestinal damage and noninfectious diarrhea. On the other hand, severe constipation or paralytic ileus before engraftment can cause bacterial transplcation through damaged and inflamed intestinal mucosa, while it is generally difficult to distinguish infectious from noninfectious enteritis. We believe it is crucial to control defecation and constipation during this period. The current analysis suggests that fentanyl might be safer than morphine in many cases of post-HCT stomatitis, if not all. Fentanyl may be a drug of first choice for oral mucositis during the early period of allo-HCT.

\section{REFERENCES}

[1] S. McCann, M. Schwenkglenks, P. Bacon, H. Einsele, A. D'Addio, et al., "The Prospective Oral Mucositis Audit: Relationship of Severe Oral Mucositis with Clinical and Medical Resource Use Outcomes in Patients Receiving High-Dose Melphalan or BEAM-Conditioning Chemotherapy and Autologous SCT," Bone Marrow Transplant, Vol. 43, No. 2, 2009, pp. 141-147.

\section{doi:10.1038/bmt.2008.299}

[2] S. R. Fanning, L. Rybicki, M. Kalaycio, S. Andresen, E. Kuczkowski, et al., "Severe Mucositis Is Associated with Reduced Survival after Autologous Stem Cell Transplantation for Lymphoid Malignancies," British Journal of Haematology, Vol. 135, No. 3, 2006, pp. 374-381. doi:10.1111/j.1365-2141.2006.06323.x

[3] P. J. Stiff, H. Erder, W. I. Bensinger, C. Emmanouilides, T. Gentile, et al., "Reliability and Validity of a Patient Self-Administered Daily Questionnaire to Assess Impact of Oral Mucositis (OM) on Pain and Daily Functioning in Patients Undergoing Autologous Hematopoietic Stem Cell Transplantation (HSCT)," Bone Marrow Transplant, Vol. 37, No. 4, 2006, pp. 393-401. doi:10.1038/sj.bmt. 1705250

[4] S. Ahmedzai and D. Brooks, "Transdermal Fentanyl versus Sustained-Release Oral Morphine in Cancer Pain: Preference, Efficacy and Quality of Life. The TTS-Fentanyl Comparative Trial Group," Journal of Pain and Symptom Management, Vol. 13, No. 5, 1997, pp. 254-261. http://www.ncbi.nlm.nih.gov/pubmed/9185430

[5] B. Donner, M. Zenz, M. Tryba and M. Strumpf, "Direct Conversion from Oral Morphine to Transdermal Fentanyl: A Multicenter Study in Patients with Cancer Pain," Pain, Vol. 64, No. 3, 1996, pp. 527-534.

http://www.ncbi.nlm.nih.gov/pubmed/8783318

[6] L. Radbruch, R. Sabatowski, G. Loick, C. Kulbe, M. Kasper, et al., "Constipation and the Use of Laxatives: A Comparison between Transdermal Fentanyl and Oral Morphine," Palliative Medicine, Vol. 14, No. 2, 2000, pp. 111-119. http://www.ncbi.nlm.nih.gov/pubmed/10829145

[7] A. Herz and H. J. Teschemacher, "Activities and Sites of Antinociceptive Action of Morphine-Like Analgesics," In: N. J. Harper and A. B. Simmonds, Eds., Advances in Drug Research, Academic Press, London, 1971, pp. 79 121. 